\title{
Antenatal sonographic assessment of cross sectional area of umbilical cord components and its reference value in normal pregnancy
}

\author{
Khizer Hussain Afroze ${ }^{1 *}$, Lakshmiprabha Subash ${ }^{1}$, Anand S. H. ${ }^{2}$
}

\begin{abstract}
${ }^{1}$ Department of Anatomy, ${ }^{2}$ Department of Radio Diagnosis, Sri Siddhartha Medical College, Tumakuru, Karnataka, India
\end{abstract}

Received: 15 August 2018

Accepted: 01 September 2018

*Correspondence:

Dr. Khizer Hussain Afroze,

E-mail: drafroze.homeo@gmail.com

Copyright: (c) the author(s), publisher and licensee Medip Academy. This is an open-access article distributed under the terms of the Creative Commons Attribution Non-Commercial License, which permits unrestricted non-commercial use, distribution, and reproduction in any medium, provided the original work is properly cited.

\begin{abstract}
Background: Measuring the cross-sectional area of umbilical components in normal pregnant women helps in assessing the fetal abnormalities. Very few literatures were available on evaluation of reference values of cross sectional areas of umbilical cord components. The present study was conducted with the aim to determine the normal reference values of cross sectional areas of umbilical arteries, umbilical vein and Wharton's jelly and to correlate them with the gestational age of the fetus.

Methods: A cross sectional study was conducted on 300 normal pregnant women at the Department of Radiodiagnosis, Sri Siddhartha Medical College, Tumakuru, Karnataka to assess the reference range of cross sectional areas of umbilical cord arteries, umbilical vein and Wharton's jelly at different gestational age of the fetus to analyze their growth.

Results: A statistically significant correlation was observed between cross sectional areas of umbilical artery and vein and gestational age before and after 34 weeks ( $\mathrm{p}=0.005$ and 0.006 respectively) but no significant correlation was noticed with the cross-sectional area of Wharton's jelly $(\mathrm{p}=0.088)$.

Conclusions: Cross sectional area measurements of umbilical cord components can be considered as important tools for estimation of fetal growth.
\end{abstract}

Keywords: Normal pregnancy, Ultrasonography, Umbilical cord components

\section{INTRODUCTION}

Umbilical cord is comprised of two umbilical arteries, one umbilical vein and Wharton's jelly surrounding them and by fragments of the allantoids. It is responsible for feto-maternal blood flow. ${ }^{1}$ Assessment of morphometric alterations of umbilical cord by prenatal sonography at different gestational ages permits the identification of adverse perinatal outcomes. ${ }^{2,3}$

Many authors established the morphology of umbilical cord and components but very few studies were conducted on determining the reference ranges of the cross-sectional area of the portions of the umbilical cord. $^{4-7}$

Alteration of these reference ranges validates antenatal and perinatal complications including preeclampsia, growth restriction, pregnancy induced hypertension, fetal heart rate disturbances, fetal aneuploidy, macrosomy, and intrauterine demise. ${ }^{8-10}$

The purpose of the present study was to determine the reference range measurements, via ultrasonography, for the cross-sectional areas of umbilical arteries, umbilical vein and Wharton jelly at different gestational ages. 


\section{METHODS}

The present cross-sectional study was done on 300 pregnant women having no complications, with gestational age between 28-39 weeks at the Department of Radiodiagnosis, Sri Siddhartha Medical College, Tumakuru, Karnataka, India during the period from January 2015-June 2018. Informed consents were collected from all the patients.

\section{Selection criteria}

Normal singlet pregnant women between the age group of 20-35 years and gestational age 28-39 weeks based on last menstrual period (LMP) were included in the study. Exclusion criteria were pregnancies related with comorbid conditions like gestational diabetes, preeclampsia, PIH, IUGR, oligohydramnios, polyhydramnios and Intrauterine Death (IUD). All foetuses with the congenital anomalies were excluded.

After getting approval from Institutional ethics committee, all the patients underwent a routine antenatal sonogram performed by a single operator on a commercially available ultrasound machine GE voluslon pro730 with a $3-3.5-\mathrm{MHz}$ curvilinear (Convex) abdominal probe. A single measurement of each parameter was recorded. The sonographic cross-sectional areas of the umbilical cord, umbilical arteries and umbilical vein were measured in a plane close to the cord insertion at the fetal abdomen. The cord and its vessels were manually circled, and their cross-sectional areas were automatically calculated by the ultrasonography (Figure 1). The cross-sectional area of the Wharton jelly was obtained by subtracting the total vessel area from the total cross-sectional area of the umbilical cord.

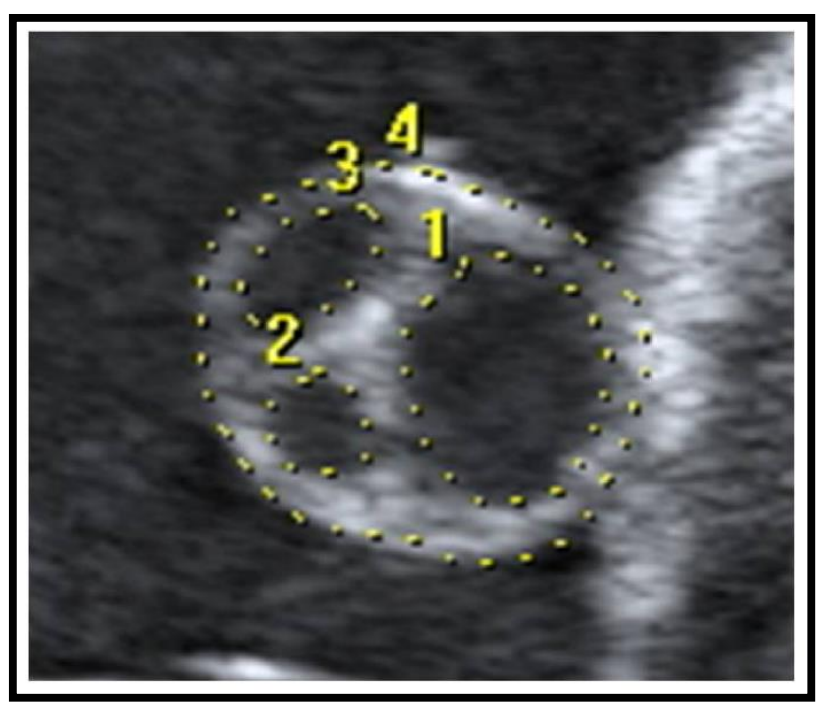

Figure 1: Ultrasonographic cross sectional view of the umbilical cord and its components. 1) cross sectional area of umbilical vein, 2) and 3) cross sectional area of umbilical artery, 4) cross-sectional area of umbilical cord.

\section{Statistical analysis}

The data obtained were statistically analysed using SPSS software version 18.0. The mean and standard deviation of the cross-section area (CSA) of the umbilical arteries, vein and Wharton's jelly were calculated in accordance with gestational age. The 5th, 10th, 50th, 90th and 95th percentile for gestational age for the measurements were also calculated. Polynomial regression analysis was performed to identify the regression curves that best fitted the data point. Student test was done for calculating the mean and standard deviation of the CSA and circumference of the umbilical cord, vein and arteries in each group (before and after 34 weeks of gestational age). Statistical significance was considered when $\mathrm{p}$ value was $>0.05$.

\section{RESULTS}

Table 1 presents the patients characteristics. The mean age of the patients was 25.1 years with an average gestational age of 34.3 weeks. Average birth weight of the neonates was $2855 \mathrm{gm}$. Majority of them were nulliparous $(51 \%)$.

Table 1: Patient characteristics $(n=300)$.

\begin{tabular}{|ll|}
\hline Characteristics & Mean \pm S.D \\
\hline Maternal age (years) & $25.10 \pm 3.61$ \\
\hline Gestational age at delivery (weeks) & $34.36 \pm 2.69$ \\
\hline Birth weight $(\mathrm{g})$ & $2855 \pm 418.6$ \\
\hline Parity & $\mathbf{n}(\%)$ \\
\hline Nullipara & $153(51 \%)$ \\
\hline$>1$ & $147(49 \%)$ \\
\hline
\end{tabular}

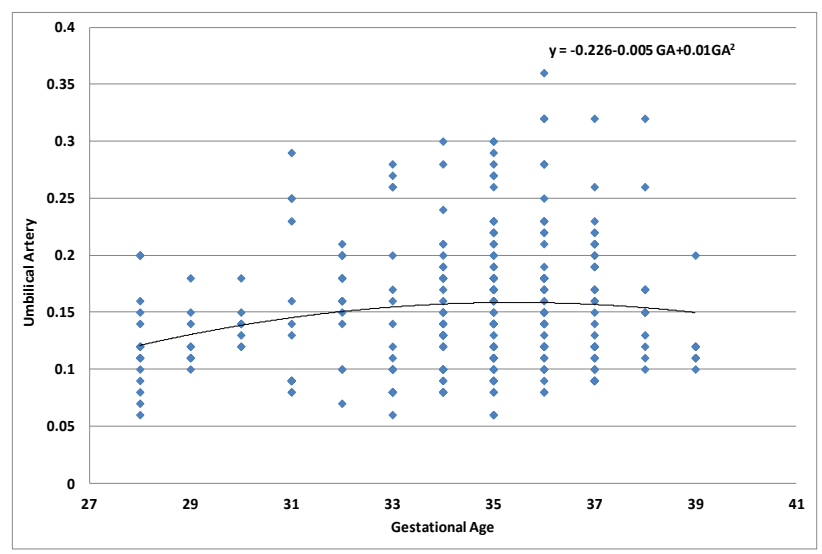

The regression equation for the mean umbilical artery (y) according to gestational age $(x)$ was $y=-0.226-0.005$ $\mathrm{GA}+0.01 \mathrm{GA} 2$.

Figure 2: Scatter diagram of umbilical artery with gestational age.

Table 2 presents the mean cross-sectional areas of the umbilical arteries, umbilical veins and Wharton's jelly for each gestational age respectively. The mean crosssectional area of umbilical artery and Wharton's jelly was 
increased from 28th gestational week to 36th week, followed by decrease from 37 th week as shown in Figure 2 and 3.

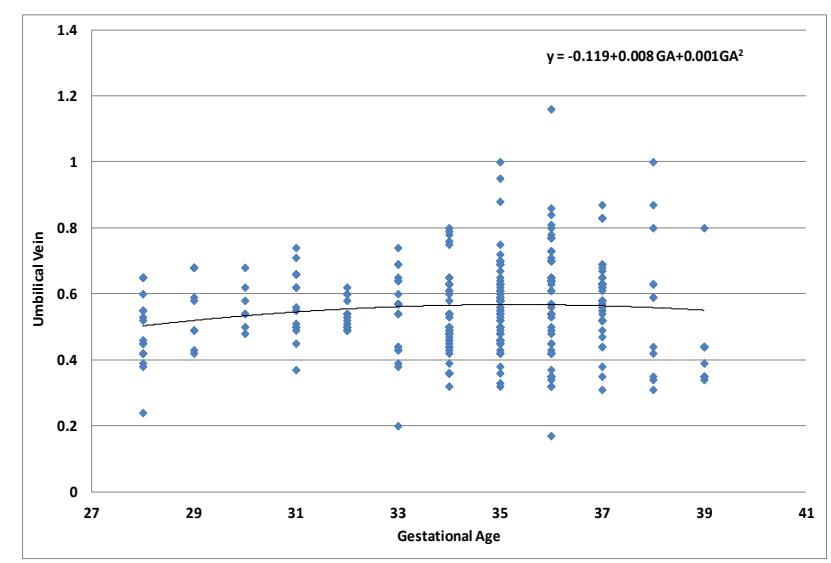

The regression equation for the mean Umbilical vein (y) according to gestational age (x) was $\mathrm{y}=-0.119+0.008$ $\mathrm{GA}+0.001 \mathrm{GA} 2$.

Figure 3: Scatter diagram of umbilical vein with gestational age.
Figure 4 presents that the curve for mean cross sectional area of umbilical vein was increased up to 37 th week and declined on 38th and 39th gestational week (Table 2).

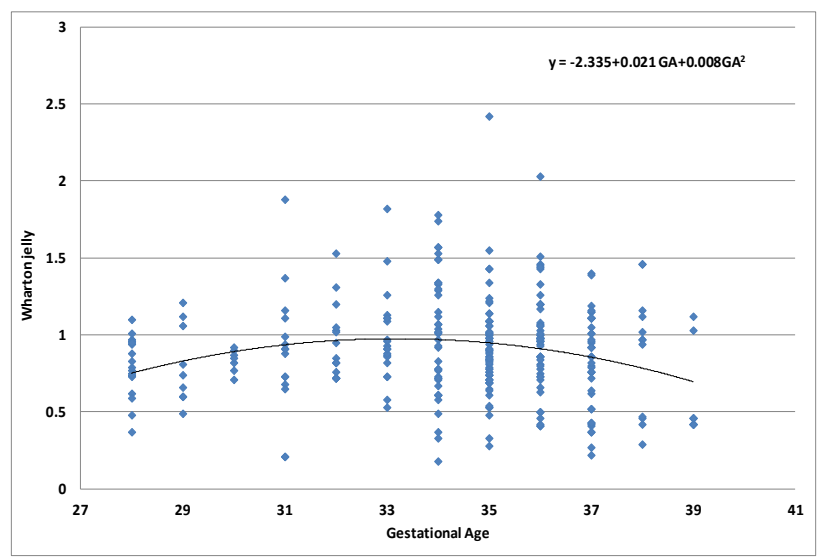

The regression equation for the mean Wharton's Jelly (y) according to gestational age ( $\mathrm{x})$ was $\mathrm{y}=-2.335+0.021$ GA+0.008GA2.

Figure 4: Scatter diagram of Wharton's jelly with gestational age.

Table 2: Descriptive mean cross-sectional areas of umbilical artery, umbilical vein and Wharton's Jelly according to gestational age.

\begin{tabular}{|c|c|c|c|c|}
\hline Gestational age & Number & $\begin{array}{l}\text { Umbilical artery cross } \\
\text { sectional area }\end{array}$ & $\begin{array}{l}\text { Umbilical vein cross } \\
\text { sectional area }\end{array}$ & $\begin{array}{l}\text { Wharton's jelly cross } \\
\text { sectional area }\end{array}$ \\
\hline Week (days) & & Mean \pm S.D $\left(\mathrm{cm}^{2}\right)$ & Mean \pm S.D $\left(\mathrm{cm}^{2}\right)$ & Mean \pm S.D $\left(\mathrm{cm}^{2}\right)$ \\
\hline $28(1-6)$ & 17 & $0.126 \pm 0.044$ & $0.490 \pm 0.112$ & $0.789 \pm 0.195$ \\
\hline $29(1-6)$ & 09 & $0.127 \pm 0.025$ & $0.560 \pm 0.106$ & $0.811 \pm 0.258$ \\
\hline $30(1-6)$ & 07 & $0.140 \pm 0.020$ & $0.563 \pm 0.070$ & $0.834 \pm 0.074$ \\
\hline $31(1-6)$ & 15 & $0.143 \pm 0.074$ & $0.573 \pm 0.104$ & $0.891 \pm 0.416$ \\
\hline $32(1-6)$ & 15 & $0.159 \pm 0.417$ & $0.534 \pm 0.045$ & $0.948 \pm 0.245$ \\
\hline $33(1-6)$ & 20 & $0.142 \pm 0.073$ & $0.536 \pm 0.132$ & $0.984 \pm 0.296$ \\
\hline $34(1-6)$ & 41 & $0.145 \pm 0.053$ & $0.530 \pm 0.126$ & $0.996 \pm 0.394$ \\
\hline $35(1-6)$ & 66 & $0.162 \pm 0.060$ & $0.568 \pm 0.127$ & $0.913 \pm 0.307$ \\
\hline $36(1-6)$ & 49 & $0.171 \pm 0.064$ & $0.585 \pm 0.182$ & $0.966 \pm 0.323$ \\
\hline $37(1-6)$ & 40 & $0.149 \pm 0.055$ & $0.595 \pm 0.122$ & $0.819 \pm 0.305$ \\
\hline $38(1-6)$ & 12 & $0.167 \pm 0.063$ & $0.581 \pm 0.222$ & $0.895 \pm 0.399$ \\
\hline $39(1-6)$ & 09 & $0.123 \pm 0.30$ & $0.433 \pm 0.144$ & $0.579 \pm 0.282$ \\
\hline
\end{tabular}

Table 3: Correlation of mean cross-sectional areas of umbilical artery, umbilical vein and Wharton's Jelly before and after 34 weeks of gestational age.

\begin{tabular}{|c|c|c|c|c|c|c|c|c|}
\hline & Gestational age (weeks) & $\mathbf{N}$ & Mean & SD & Min. & Max. & t value & P value \\
\hline \multirow{3}{*}{$\begin{array}{l}\text { Umbilical } \\
\text { artery }\end{array}$} & $<34$ & 79 & 0.129 & 0.087 & 0.05 & 0.70 & \multirow{3}{*}{7.861} & \multirow{3}{*}{0.005} \\
\hline & $>34$ & 221 & 0.153 & 0.058 & 0.06 & 0.36 & & \\
\hline & Total & 300 & 0.147 & 0.067 & 0.05 & 0.70 & & \\
\hline \multirow{3}{*}{$\begin{array}{l}\text { Umbilical } \\
\text { vein }\end{array}$} & $<34$ & 79 & 0.506 & 0.148 & 0.20 & 1.05 & \multirow{3}{*}{7.711} & \multirow{3}{*}{0.006} \\
\hline & $>34$ & 221 & 0.560 & 0.151 & 0.17 & 1.16 & & \\
\hline & Total & 300 & 0.546 & 0.152 & 0.17 & 1.16 & & \\
\hline \multirow{3}{*}{$\begin{array}{l}\text { Wharton's } \\
\text { jelly }\end{array}$} & $<34$ & 79 & 0.983 & 0.396 & 0.21 & 1.88 & \multirow{3}{*}{2.922} & \multirow{3}{*}{0.088} \\
\hline & $>34$ & 221 & 0.903 & 0.346 & 0.18 & 2.42 & & \\
\hline & Total & 300 & 0.924 & 0.361 & 0.18 & 2.42 & & \\
\hline
\end{tabular}


Statistically significant correlation was observed between cross sectional areas of umbilical artery and vein when compared with gestational age of pregnant women before and after 34 weeks ( $\mathrm{p}=0.005$ and 0.006 respectively) but no significant correlation was noticed with the cross- sectional area of Wharton's jelly $(\mathrm{p}=0.088)$ (Table 3$)$. Table 4-6 shows the 5th, 10th, 25th, 50th, 75th, 90th, and 95th percentiles for the measurements of the crosssectional area of the components of umbilical cord for each gestational age considered.

Table 4: Percentile distribution of umbilical artery cross sectional area.

\begin{tabular}{|llllllll|}
\hline Gestational age & Percentiles & & & & & \\
\hline Week (days) & $\mathbf{5}$ & $\mathbf{1 0}$ & $\mathbf{2 5}$ & $\mathbf{5 0}$ & $\mathbf{7 5}$ & $\mathbf{9 0}$ & $\mathbf{9 5}$ \\
\hline $28(1-6)$ & 0.06 & 0.068 & 0.095 & 0.12 & 0.155 & 0.2 & - \\
\hline $29(1-6)$ & 0.1 & 0.1 & 0.11 & 0.12 & 0.145 & - & - \\
\hline $30(1-6)$ & 0.12 & 0.12 & 0.12 & 0.14 & 0.15 & - & - \\
\hline $31(1-6)$ & 0.08 & 0.08 & 0.09 & 0.09 & 0.23 & 0.266 & - \\
\hline $32(1-6)$ & 0.07 & 0.088 & 0.14 & 0.16 & 0.2 & 0.204 & - \\
\hline $33(1-6)$ & 0.061 & 0.08 & 0.08 & 0.105 & 0.193 & 0.269 & 0.28 \\
\hline $34(1-6)$ & 0.08 & 0.08 & 0.1 & 0.13 & 0.18 & 0.21 & 0.276 \\
\hline $35(1-6)$ & 0.08 & 0.09 & 0.11 & 0.16 & 0.2 & 0.263 & 0.287 \\
\hline $36(1-6)$ & 0.085 & 0.1 & 0.12 & 0.16 & 0.2 & 0.28 & 0.32 \\
\hline $37(1-6)$ & 0.09 & 0.09 & 0.103 & 0.135 & 0.198 & 0.22 & 0.259 \\
\hline $38(1-6)$ & 0.1 & 0.103 & 0.123 & 0.15 & 0.17 & 0.302 & - \\
\hline $39(1-6)$ & 0.1 & 0.1 & 0.11 & 0.12 & 0.12 & - & - \\
\hline
\end{tabular}

Table 5: Percentile distribution of umbilical vein cross sectional area.

\begin{tabular}{|llllllll|}
\hline Gestational age & Percentiles & & & & & \\
\hline Week (days) & $\mathbf{5}$ & $\mathbf{1 0}$ & $\mathbf{2 5}$ & $\mathbf{5 0}$ & $\mathbf{7 5}$ & $\mathbf{9 0}$ & $\mathbf{9 5}$ \\
\hline $28(1-6)$ & 0.24 & 0.352 & 0.42 & 0.46 & 0.575 & 0.65 & - \\
\hline $29(1-6)$ & 0.42 & 0.42 & 0.46 & 0.58 & 0.68 & - & - \\
\hline $30(1-6)$ & 0.48 & 0.48 & 0.5 & 0.54 & 0.62 & - & - \\
\hline $31(1-6)$ & 0.37 & 0.418 & 0.5 & 0.56 & 0.66 & 0.722 & - \\
\hline $32(1-6)$ & 0.49 & 0.49 & 0.5 & 0.52 & 0.58 & 0.608 & - \\
\hline $33(1-6)$ & 0.209 & 0.381 & 0.433 & 0.57 & 0.64 & 0.69 & 0.737 \\
\hline $34(1-6)$ & 0.36 & 0.36 & 0.445 & 0.5 & 0.62 & 0.758 & 0.789 \\
\hline $35(1-6)$ & 0.367 & 0.427 & 0.48 & 0.57 & 0.63 & 0.7 & 0.834 \\
\hline $36(1-6)$ & 0.32 & 0.35 & 0.44 & 0.61 & 0.705 & 0.8 & 0.85 \\
\hline $37(1-6)$ & 0.352 & 0.44 & 0.52 & 0.62 & 0.645 & 0.816 & 0.83 \\
\hline $38(1-6)$ & 0.31 & 0.319 & 0.368 & 0.59 & 0.758 & 0.961 & - \\
\hline $39(1-6)$ & 0.34 & 0.34 & 0.35 & 0.39 & 0.44 & - & - \\
\hline
\end{tabular}

Table 6: Percentile distribution of Wharton's jelly cross sectional area.

\begin{tabular}{|llllllll|}
\hline Gestational age & Percentiles & & & & & & \\
\hline Week (days) & $\mathbf{5}$ & $\mathbf{1 0}$ & $\mathbf{2 5}$ & $\mathbf{5 0}$ & $\mathbf{7 5}$ & $\mathbf{9 0}$ & $\mathbf{9 5}$ \\
\hline $28(1-6)$ & 0.37 & 0.458 & 0.675 & 0.79 & 0.955 & 1.028 & - \\
\hline $29(1-6)$ & 0.49 & 0.49 & 0.6 & 0.74 & 1.09 & - & - \\
\hline $30(1-6)$ & 0.71 & 0.71 & 0.77 & 0.85 & 0.9 & - & - \\
\hline $31(1-6)$ & 0.21 & 0.21 & 0.68 & 0.91 & 1.11 & 1.574 & - \\
\hline $32(1-6)$ & 0.72 & 0.72 & 0.72 & 0.85 & 1.05 & 1.398 & - \\
\hline $33(1-6)$ & 0.533 & 0.595 & 0.83 & 0.92 & 1.11 & 1.458 & 1.803 \\
\hline $34(1-6)$ & 0.334 & 0.508 & 0.715 & 1.01 & 1.315 & 1.562 & 1.723 \\
\hline $35(1-6)$ & 0.498 & 0.589 & 0.74 & 0.885 & 1.03 & 1.226 & 1.43 \\
\hline $36(1-6)$ & 0.415 & 0.5 & 0.765 & 0.97 & 1.125 & 1.44 & 1.485 \\
\hline $37(1-6)$ & 0.275 & 0.374 & 0.545 & 0.86 & 1.095 & 1.159 & 1.38 \\
\hline $38(1-6)$ & 0.29 & 0.329 & 0.462 & 0.97 & 1.15 & 1.46 & - \\
\hline $39(1-6)$ & 0.42 & 0.42 & 0.42 & 0.46 & 0.745 & - & - \\
\hline
\end{tabular}




\section{DISCUSSION}

Umbilical cord is a unique organ consisting of two umbilical arteries, one umbilical vein and Wharton's jelly, which are sophisticated structures and performs vital functions to supply the necessary requirements to the foetus from the mother during the period of pregnancy. ${ }^{11}$ The umbilical cord begins to appear from the $4^{\text {th }}-8^{\text {th }}$ weeks of gestation from the amnion tissue from the body stalk, the omphalomesenteric duct and the umbilical coelom and establishment of blood flow within the cord starts by the end of the 5 th week of gestation. ${ }^{12,13}$

The left and right umbilical arteries are developed from the internal iliac arteries and supplies deoxygenated blood from foetus to the placenta. ${ }^{14}$ Umbilical veins arise from the convergence of venules that drain the extraembryonic allantois. ${ }^{15}$ The right umbilical vein will disappear at the end of $6^{\text {th }}$ week of gestation and left umbilical vein persists till the birth of the baby. It carries oxygenated blood from the placenta to the foetus. ${ }^{16}$ Wharton's jelly is a mucous connective tissue that surrounds the umbilical cord vessels. It originates from extra embryonic mesoderm and composed of proteoglycans and myofibroblasts. Hyaluronic acid is the important proteoglycan of Wharton's jelly and helps in resisting external pressure and acts as a physical buffer in the regulation of fetoplacental circulation. ${ }^{17}$

During foetal development, a number of abnormalities affect the umbilical cord that results in intrauterine growth restriction to fetal demise. They are related to morphology, cord insertion, cord length, cord diameter, number of vessels and blood flow. ${ }^{18}$ The most important among them was single umbilical artery. About $1 \%$ of singleton and about $5 \%$ of multiple pregnancies have only one umbilical artery. This leads to increase the risk of birth defects such as chromosomal abnormalities and defects in cardiovascular, urinary tract and central nervous systems. ${ }^{19,20}$

Umbilical cord cysts (true or false) are found in about $3 \%$ of pregnancies. Both types of cysts are associated with chromosomal abnormalities, abdominal and kidney defects in the foetus. About $1 \%$ of the babies are born with umbilical cord knots. Tight knots result in miscarriage or stillbirth in $5 \%$ of cases. ${ }^{19}$ Nuchal cord abnormality was seen in about $25 \%$ of babies. Most of them are usually healthy but some shows heart rate abnormalities during labor and after delivery. ${ }^{21}$ Vasa previa is another abnormal condition that arises when umbilical cord vessels are unprotected by Wharton's jelly that leads to tearing of blood vessels and can result in life-threatening bleeding in the baby. ${ }^{22}$

Most of these abnormalities are diagnosed by noninvasive procedures before delivery but some are observed during or after delivery. Ultrasound and Doppler flow techniques helps in visualizing the morphology and feotal blood flow through umbilical cord vessels. $^{23,24}$ By assessing the amount of blood flow through the umbilical artery during both fetal systole and diastole, an overall measure of fetal health can be obtained. But some clinical conditions such as fetal anaemia, high risk for several congenital and genetic defects like Down's syndrome necessitate invasive approach. In such conditions foetus blood samples are to be collected by cordocentesis. ${ }^{25}$

The two umbilical arteries and umbilical vein forms a cylindrical helix structure measuring one coil per $5 \mathrm{~cm}$ in length. It develops around 40 spirals with some straight portions reversal of spiral in between in most of the cases. ${ }^{26}$ Clinically hypocoiled umbilical cords have been associated with incidence of interventional deliveries, higher cord $\mathrm{pH}$ and heart rate disturbances and hyper coiling of umbilical cords were associated with preterm labour, preterm birth and growth restriction. ${ }^{27}$

Hence it is very important to measure the cross-sectional areas of umbilical cord components at different stages of fetal development. The changes in these components are responsible for variations in umbilical cord dimensions. During gestational period, the umbilical cord has an average length of $50-60 \mathrm{~cm} .{ }^{28}$ The cord length less than $30 \mathrm{~cm}$ is termed as short and associated with intrauterine growth restriction, congenital abnormalities, delayed foetal descent, premature placental separation. ${ }^{29}$ The cord length more than $100 \mathrm{~cm}$ termed as long cord and was related with prolapse, looping of the cord around the foetal neck, entanglement, distress and intrauterine demise. $^{30}$

Very few studies have been conducted for assessing the relationship between cross sectional areas of umbilical cord components and gestational age. The present study is the first among Indian population to assess the reference interval of umbilical cord components at different gestational age. The first study to evaluate the cross-sectional areas of umbilical cord and its portions by sonography were done by Weissman and colleagues. ${ }^{7}$ They determined reference measures for the diameters of umbilical arteries, umbilical vein and Wharton's jelly and their findings suggested that diameter of the cord increases with the increase in gestational age. Raio and his co-workers established reference measures for the cross-sectional areas of umbilical cord and found an increase in the cross-sectional area of umbilical cord upto 32 weeks followed by its fall. ${ }^{8}$

The present study revealed the reference measures for the cross-sectional areas of umbilical artery, umbilical vein and Wharton's jelly.

Umbilical arteries carry deoxygenated and nutrient depleted blood from foetus to placenta. Any abnormality in the health of foetus can be identified by measuring the amount of forward blood flow in umbilical arteries during systole and diastole. ${ }^{25}$ It is sufficient to measure diameter of one umbilical artery as both the arteries have similar 
lumen diameters. However, there will be a difference in about $0.7-1.4 \%$ cases, one of the arteries will be smaller than the other with a difference of around $1-3 \mathrm{~mm} \cdot{ }^{4,31} \mathrm{In}$ the present study, an increase in the cross-sectional area of umbilical artery was noticed from 28th gestational week to $36^{\text {th }}$ week, followed by decrease from 37 th week. These observations were in accordance with the observations of Togni et al. ${ }^{4}$ In another study by Skulstad et al, an increase in umbilical artery diameter was noticed according to gestational age up to the 31 st week and remaining stable to the end of the gestation. ${ }^{32}$

The average diameter of umbilical vein ranges from 2 $\mathrm{mm}$ at $14-15$ weeks of gestation to $7-8 \mathrm{~mm}$ to term. ${ }^{7}$ In the present study, the mean cross-sectional area of umbilical vein was increased up to 37 th week and declined on 38th and 39th gestational week. These results were almost similar to the observations noticed by Togni et al. ${ }^{4}$ In his study, the cross-sectional area of the umbilical vein increased up to the $34^{\text {th }}$ week, stabilized in the $38^{\text {th }}$ week, and declined from the $39^{\text {th }}$ week onwards.

Cross sectional areas of Wharton's jelly increase with gestational period. Changes in the cross-sectional areas of Wharton's jelly describe the abnormal conditions during gestation. Absence of Wharton's jelly around the umbilical cord vessels found in cases of perinatal mortality whereas larger cross sectional area of Wharton's jelly defined in conditions of diabetes mellitus. ${ }^{5,7}$ The mean cross sectional areas of Wharton's jelly was $0.79 \mathrm{~cm}^{2}$ during $36^{\text {th }}$ week to $40^{\text {th }}$ week of gestation. ${ }^{33}$ In the present study, the cross sectional area of Wharton's jelly increased from $28^{\text {th }}$ gestational week to $36^{\text {th }}$ week, followed by decrease from $37^{\text {th }}$ week. Similar observations were also made by Togni et al. ${ }^{4}$

In present study, statistically significant correlation was established between cross sectional areas umbilical arteries $(p<0.005)$ and veins $(p<0.006)$. These results were consistent with the findings of Rostamzadeh et al. ${ }^{34}$ However, no significant association was observed between cross sectional areas of Wharton's jelly and gestational age. This was in agreement with the observations of Barbieri et al. ${ }^{5}$ This week correlation between Wharton's jelly and gestational age was also supported by Ghezzi et al. ${ }^{9}$ This might be due to the result of the overlap of two altered conditions as a function of gestational age; i.e., a strong correlation for earlier gestational ages and a weak correlation for later gestational ages.

\section{CONCLUSION}

The findings of the study concluded that the crosssectional area of umbilical cord components are to be considered as an important evaluating factors at different gestational ages for assessing the fetal growth. The ranges obtained in this study can be taken as references for further studies to correlate with the anthropometric parameters to estimate the fetal growth disorders and pregnancy disorders such as PIH and gestational diabetes.

Funding: No funding sources

Conflict of interest: None declared

Ethical approval: The study was approved by the Institutional Ethics Committee

\section{REFERENCES}

1. Wang HS, Hung SC, Peng ST, Huang CC, Wei HM, Guo YJ, et al. Mesenchymal stem cells in the Wharton's jelly of the human umbilical cord. Stem Cells. 2004;22:1330-7.

2. Qureshi F, Jacques SM. Marked segmental thinning of the umbilical cord vessels. Arch Pathol Lab Med. 1994;118:828-30.

3. Sun Y, Arbucku S, Hocking G, Billso V. Umbilical cord stricture and intrauterine fetal death. Pediatr Pathol Lab Med. 1995;5:723-32.

4. Togni FA, Araújo E, Vasques FA, Moron AF, Torloni MR, Nardozza LM. The cross-sectional area of umbilical cord components in normal pregnancy. Int J Gynecol Obstet. 2007;96(3):156-61.

5. Barbieri C, Cecatti JG, Surita FG, Marussi EF, Costa JV. Sonographic measurement of the umbilical cord area and the diameters of its vessels during pregnancy. J Obstetrics Gynaecol. 2012;32(3):230-6.

6. Afroze KH, Prabha SL, Chandrakala V, Deepak M. Sonographic Estimation of Umbilical Cord Crosssection Area and its Reference Value in Normal Pregnancy. J Clin Diagn Res. 2017;11(8):4-6.

7. Weissman A, Jakobi P, Bronshtein M, Golstein I. Sonographic measurements of the umbilical cord and vessels during normal pregnancies. J Ultrasound Med. 1994;13:11-4.

8. Raio L, Ghezzi F, Di Naro E, Gomez R, Franchi M, Mazor M, et al. Sonographic measurement of the umbilical cord and fetal anthropometric parameters. Eur J Obstet Gynecol Reprod Biol. 1999;83:131-5.

9. Ghezzi F, Raio L, Di Naro E, Franchi M, Balestredi D, D'Addario V. Nomogram of Wharton's jelly as depicted in the sonographic cross section of the umbilical cord. Ultrasound Obstet Gynecol. 2001;18:121-5.

10. Skulstad SM, Ulriksen M, Rasmussen S, Kiserud T. Effect of umbilical ring constriction on Wharton's jelly. Ultrasound Obstet Gynecol. 2006;28:692-8.

11. Fahmy M. Anatomy of the Umbilical Cord. In: Umbilicus and Umbilical Cord. Springer, Cham; 2018: 47-56.

12. Schöni-Affolter F, Dubuis-Grieder C, Strauch E. The umbilical cord. 2007. Available at: http://www.embryology.ch/anglais/fplacenta/cordon0 1.html.

13. Cochard LR. Netter's Atlas of Human Embryology. 1st ed. New Jersey: Icon Learning Systems; 2002.

14. Standring S, editor. Gray's Anatomy: The Anatomical Basis of Clinical Practice. 40 ed. Edinburgh: Churchill Livingstone Elsevier; 2008. 
15. Blackburn ST. Maternal, Fetal, \& Neonatal Physiology: A Clinical Perspective. 3rd ed. St. Louis: Sanders Elsevier; 2007.

16. Callen PW. Ultrasonography in Obstetrics and Gynecology. 4th ed. Philadelphia: WB Saunders Company; 2000.

17. Filiz AA, Bedir Rahime H, Keskin L, Esra AK. Positive correlation between the quantity of Wharton's jelly in the umbilical cord and birth weight. Taiwanese J Obstet Gynecol. 2011;50(1):336.

18. Moshiri M, Zaidi SF, Robinson TJ, Bhargava P, Siebert JR, Dubinsky TJ, et al. Comprehensive Imaging Review of Abnormalities of the Umbilical Cord. RadioGraphics 2014;34:179-96.

19. Morgan BLG, Ross MG. Umbilical Cord Complications. emedicine.com. 2006.

20. Gossett DR, Lantz ME, Chisholm CA. Antenatal Diagnosis of Single Umbilical Artery: Is Fetal Echocardiography Warranted? Obstet Gynecol. 2002;100(5):903-8.

21. Cruikshank DW. Breech, Other Malpresentations, and Umbilical Cord Complications. In: Scott JR, et al, eds. Danforth's Obstetrics and Gynecology. 9th Edition. Philadelphia: Lippincott Williams and Wilkins; 2003: 381-395.

22. Oyelese Y, Smulian JC. Placenta Previa, Placenta Accreta, and Vasaprevia. Obstetrics Gynecol. 2006;107(4):927-41.

23. Kliman HJ. The Umbilical Cord. Available at: shttps://medicine.yale.edu/obgyn/kliman/placenta/res earch/Umbilical\%20Cord\%20EOR_163162_284_18 220_v1.pdf.

24. Deka D, Dadhwal V, Roy KK, Malhotra N, Vaid A, Mittal S. Indications of 1342 fetal cord blood sampling procedures performed as an integral part of high risk pregnancy care. J Obstet Gynaecol India. 2012;62(1):20-4.

25. Wang Y, Zhao S. Vascular Biology of the Placenta. San Rafael (CA): Morgan \& Claypool Life Sciences; 2010 .
26. Predanic M. Sonographic assessment of the umbilical cord. Ultrasound Rev Obstet Gynecol. 2005;5:105-10.

27. Di Naro E, Ghezzi F, Raio L, Franchi M, D'Addario $\mathrm{V}$, Lanzillotti G, et al. Umbilical vein blood flow in fetuses with normal and lean umbilical cord. Ultrasound Obstet Gynecol. 2001;17:224-8.

28. Di Naro E, Ghezzi F, Raio L, Franchi M, D'Addario V. Umbilical cord morphology and pregnancy outcome. Eur J Obstet Gynecol Reprod Biol. 2001;96(2):150-7.

29. Hanretty K. Obstetrics Illustrated. Edinburgh: Churchill Livingstone Elsevier; 2010.

30. Cunningham FG, Leveno KJ, Bloom SL, Hauth JC, Rouse DJ, Spong CY. Williams Obstetrics. 23rd ed. New York: McGraw Hill Medical; 2010.

31. Strong TH Jr, Elliot JP, Radin TG. Non-coiled umbilical blood vessels: a marker for the fetus at risk. Obstetrics and Gynecol. 1993;81:409-11.

32. Skulstad SM, Rasmussen S, Seglem S, Svanaes RH, Aareskjold HM, Kiserud T. Effect of umbilical venous constriction on placental development, cord length and perinatal outcome. Early Human Development. 2005;81:325-31.

33. Chakraborty SK, Yousuf A, Banu LA, Shamim KM. A gross and histomorphological study of the umbilical cord in gestational diabetes mellitus. Bangladesh J Anatomy. 2011;9(1):21-5.

34. Rostamzadeh S, Kalantari M, Shahriari M, Shakiba M. Sonographic measurement of the umbilical cord and its vessels and their relation with fetal anthropometric measurements. Iran J Radiol. 2015;12(3):e12230.

Cite this article as: Afroze $\mathrm{KH}$, Subash L, Anand $\mathrm{SH}$. Antenatal sonographic assessment of cross sectional area of umbilical cord components and its reference value in normal pregnancy. Int J Reprod Contracept Obstet Gynecol 2018;7:3924-30. 